\title{
Assédio moral no trabalho: a compreensão dos trabalhadores sobre a
}

\author{
violência
}

\section{Thiago Soares Nunes}

Professor do Mestrado Profissional em Administração do Centro Universitário UNA. Pós-doutorado em Administração pela Universidade Estadual de Maringá (UEM) e Doutor em Administração pela

Universidade Federal de Santa Catarina (UFSC). E-mail: adm.thiagosn@ gmail.com (Brasil)

\section{Suzana da Rosa Tolfo}

Professora do Programa de Pós-Graduação em Psicologia e do Programa de Pós-graduação em Administração da Universidade Federal de Santa Catarina (UFSC). Doutora em Administração pela Universidade Federal de Rio Grande do Sul (UFRGS). E-mail: s.r.tolfo@ufsc.br (Brasil)

\section{Leonor María Cantera Espinosa}

Professora Titular e Diretora do Departamento de Psicologia Social da Faculdade de Psicologia da Universidade Autônoma de Barcelona (UAB/Espanha). Doutora em Psicologia pela Universidade de Porto Rico e em Psicologia Social pela UAB. E-mail: leonor.cantera@uab.cat (Espanha)

\section{RESUMO}

O assédio moral no trabalho é uma situação já recorrente há muito tempo. Porém, foi somente nas últimas décadas que foi identificado como um fenômeno destruidor do ambiente laboral, não apenas provocando a diminuição da produtividade, mas também favorecendo o absenteísmo devido aos efeitos/consequências que provoca. Por sua vez, uma das grandes dificuldades de combater e coibir a violência é a informação sobre ele, seu conceito e características. Nesse sentido, o presente artigo teve por objetivo descrever a definição de assédio moral no trabalho a partir do relato dos participantes sobre o tema em um termo/palavra. Para tanto foram utilizadas três pesquisas que ocorreram em 2008, 2010, e 2014-2015, tendo como público-alvo trabalhadores de diversos setores, como por exemplo, bancário, docentes e técnico-administrativos, saúde, justiça, e demais. Como conclusões, os participantes definiram o assédio moral prioritariamente por aspectos da prática hostil, como humilhação, desrespeito, abuso; e, em sequência, como uma consequência/efeito, como vergonha, medo, raiva. Verificou-se ainda que existe similaridade dos termos utilizados pelos participantes das pesquisas de 2008 até 2015.

Palavras-chave: Assédio moral. Consequência. Práticas hostis. 


\title{
Workplace bullying: the workers understanding about violence
}

\begin{abstract}
Workplace bullying is an old situation. However, in the last few decades it was actually identified as a destructive work environment, not only causing a decrease in productivity, but also favoring the absenteeism due to the effects/consequences that it causes (Hirigoyen, 2008). One of the major difficulties to fight against and prevent violence is information about it, the concept and its characteristics. The purpose of this article was to describe the definition of workplace bullying from participants' answers about the topic in a term/word. In order to do so, three surveys that occurred in 2008, 2010 and 2014-2015 were used, with participants from many sectors, such as banking, health system, justice, education, technical and administrative roles, and others. As a conclusion, the participants primarily defined workplace bullying as hostile practice aspects, such as humiliation, disrespect, abuse; and in sequence as a consequence/effect such as shame, fear, anger. It was also verified that there is similarity of the terms used by the research participants from 2008 to 2015.
\end{abstract}

Keywords: Workplace bullying. Consequences. Hostile practice.

\section{Como referenciar em APA:}

Nunes, T. S., Tolfo, S. R. \& Espinosa, L. M. C. (2018). Assédio moral no trabalho: a compreensão dos trabalhadores sobre a violência. R.G.Secr.,GESEC, 9(2). DOI:

\section{Como referenciar em ABNT:}

NUNES, T. S.; TOLFO, S. R.; ESPINOSA, L. M. C. Assédio moral no trabalho: a compreensão dos trabalhadores sobre a violência. R.G.Secr.,GESEC, v. 9, n. 2, 2018. DOI:
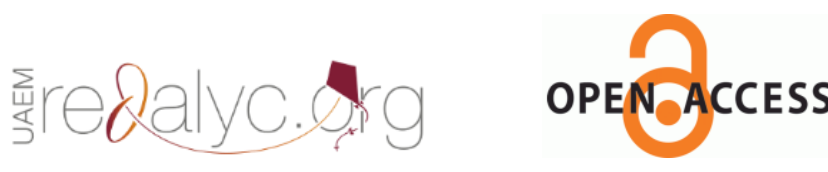


\section{Introdução}

O trabalhador tem como um de seus objetivos ou desejos de que o seu trabalho tenha sentido. Ao ingressar em uma organização, busca, entre outras coisas, fortalecer seus valores que refletem em autênticas necessidades de que seu trabalho seja um veículo que o conduza a uma transformação positiva. Embora Sina (2007, p. 127) afirme que há "profissionais que abdiquem de sua dignidade aceitando tratamento hostil e desrespeitoso". A sequência acumulativa e repetitiva desses comportamentos configurará um fenômeno invisível que vem merecendo especial atenção das organizações, dos trabalhadores, dos acadêmicos e da sociedade como um todo devido aos prejuízos que este provoca - esse fenômeno é chamado de assédio moral no trabalho.

Compreende assédio moral no trabalho como repetidos e frequentes ações, palavras, escritos, gestos, comportamentos, expressões, dirigidas a um ou mais indivíduos, de forma consciente ou inconsciente, que tem por objetivo humilhar, constranger, ofender o alvo. Não obstante, tal tema não é de conhecimento comum entre a população, ou em muitos casos, temse seu conceito utilizado de forma errônea nas relações de trabalho, bem como a noção errada da vítima.

O artigo tem como objetivo descrever a definição de assédio moral no trabalho a partir do relato dos participantes sobre o tema em um termo. Para tanto utilizaram-se pesquisas realizadas em momentos distintos que possuem o mesmo questionamento: "defina assédio moral no trabalho em um termo/palavra". Procurou-se, portanto, compreender qual o significado que os respondentes têm em relação ao assédio moral, não julgando critérios como frequência e duração que são importantes para a caracterização real do fenômeno.

\section{Assédio moral no trabalho}

Existem diversos termos que são utilizados para descrever o assédio moral, por exemplo: bullying, mobbing, harassement, abuso emocional, maus-tratos, incivilidade, agressão, comportamentos hostis, comportamentos inaceitáveis, comportamentos aversivos (Beswick, Gore \& Palferman, 2006), psicoterror, terror psicológico (Leymann, 1990; 1996), ijime, whistleblower (Hirigoyen, 2006), abuso emocional, comportamentos hostis, agressão no local de trabalho, dentre outros. A diferença de alguns destes termos muitas vezes reflete onde a pesquisa foi realizada, por exemplo, nos países do Reino Unido é comum utilizarem o termo 
bullying, na Alemanha, Áustria e Escandinávia (Dinamarca, Noruega, Suécia e Finlândia) o termo mobbing é mais utilizado, nos Estados Unidos utilizam-se emotional abuse e mobbing (Beswick et al., 2006), ijime no Japão, harcèlement moral na França (Hirigoyen, 2006), acoso nos países de língua espanhola.

O que se configura por assédio moral? Muitas das definições e conceitos de assédio moral são similares e complementares (Nunes \& Tolfo, 2013a; 2013b; 2015).

\section{Quadro 1 - Termos e definições sobre assédio moral no trabalho.}

\begin{tabular}{|c|c|c|}
\hline AUTOR & TERMO & DEFINIÇÃO \\
\hline $\begin{array}{l}\text { Leymann } \\
(1990,1996)\end{array}$ & $\begin{array}{c}\text { Mobbing / } \\
\text { Psychological } \\
\text { terror }\end{array}$ & $\begin{array}{l}\text { Terror psicológico ou mobbing no trabalho envolve comunicação hostil e } \\
\text { não ética direcionada de um modo sistemático por um ou mais indivíduos } \\
\text { para um indivíduo que, durante o assédio, é posto em uma posição } \\
\text { desamparada e indefesa, sendo mantido nesta condição por meio de ações } \\
\text { assediosas. }\end{array}$ \\
\hline $\begin{array}{l}\text { Einarsen, Hoel, } \\
\text { Zapf e Cooper } \\
\quad(2005)\end{array}$ & Bullying at work & $\begin{array}{l}\text { Bullying at work pode ser definido como ações e práticas repetidas, } \\
\text { dirigidas a um ou mais trabalhadores de forma deliberada ou inconsciente, } \\
\text { que são indesejados pela vítima, e causam humilhação, ofensa e angústia, } \\
\text { além de poder interferir no desempenho do trabalho e/ou causar } \\
\text { desagradável ambiente de trabalho. }\end{array}$ \\
\hline $\begin{array}{l}\text { Hirigoyen } \\
\text { (2008) }\end{array}$ & $\begin{array}{l}\text { Harcèlement } \\
\text { moral }\end{array}$ & $\begin{array}{l}\text { Harcèlement moral é toda e qualquer conduta abusiva manifestando-se, } \\
\text { sobretudo por comportamentos, palavras, atos, gestos, escritos que possam } \\
\text { trazer danos a personalidade, a dignidade ou à integridade física ou } \\
\text { psíquica de uma pessoa, pôr em perigo seu emprego ou degradar o } \\
\text { ambiente de trabalho. }\end{array}$ \\
\hline $\begin{array}{l}\text { Freitas, Heloani } \\
\text { e Barreto (2008) }\end{array}$ & Assédio moral & $\begin{array}{l}\text { Assédio moral é uma conduta abusiva, intencional, frequente e repetida, } \\
\text { que ocorre no ambiente de trabalho e que visa diminuir, humilhar, vexar, } \\
\text { constranger, desqualificar e demolir psiquicamente um indivíduo ou um } \\
\text { grupo, degradando as suas condições de trabalho, atingindo a sua } \\
\text { dignidade e colocando em risco a sua integridade pessoal e profissional. }\end{array}$ \\
\hline Piñuel (2013) & Mobbing & $\begin{array}{l}\text { Mobbing é um continuado e deliberado abuso verbal ou comportamental } \\
\text { de um ou mais trabalhadores para outro(s), com objetivo de reduzir, } \\
\text { submeter, diminuir, debilitar ou destruir psicologicamente, e que consiste } \\
\text { em comportamentos de perseguição frequentes, recorrentes e sistemáticos } \\
\text { contra o alvo. }\end{array}$ \\
\hline
\end{tabular}

Fonte: Elaborado pelos autores (2015).

Apesar da clareza dos conceitos e de sua aproximação um com outro (salvo exceção de alguns aspectos característicos do assédio) muitas vezes o assédio moral é mal interpretado e banalizado no dia a dia organizacional e na sociedade de forma geral. Para Leymann (1990; 1996) e Einarsen, Hoel, Zapf e Cooper (2005) o assédio moral pode ser tanto uma ação consciente quanto inconsciente. Por sua vez, Freitas, Heloani e Barreto (2008) e Piñuel (2013) afirmam que o assédio moral é uma prática deliberada (intencional, consciente). No entanto, todos os autores compreendem o assédio moral como uma prática frequente e duradoura, ou seja, o assédio moral não se configura como um ato isolado (isso é dano moral). A seguir, destacamos algumas situações que podem ser confundidas com o assédio moral: 
- Conflito: geralmente em um conflito as repreensões são ditas de forma aberta, e os envolvidos podem defender sua posição. Situações como transferências de postos de trabalho; remanejamento do trabalhador ou da chefia de atividades, cargos ou funções; mudanças decorrentes de prioridades da organização; podem gerar conflito, mas não se configuram como assédio moral por si mesma (Tolfo \& Oliveira, 2013);

- Situações eventuais: uma agressão pontual, a menos que tenha sido precedida de múltiplas pequenas agressões, é um ato de violência (que pode ser caracterizada como dano moral), mas não é assédio moral (Hirigoyen, 2006). O assédio moral caracterizase, sobretudo pela sua repetição;

- Más condições de trabalho: trabalhar em espaço pequeno, mal iluminado, com instalação inadequada não é assédio moral, a não ser que o trabalhador (ou grupo de trabalhadores) seja posto em tais condições com objetivo de desmerecê-lo (Hirigoyen, 2006; Tolfo \& Oliveira, 2013);

- Exigências profissionais: o assédio não deve ser confundido com atividades inerentes ao contrato de trabalho que devem ser exigidas ao trabalhador, tais como transferência e mudanças de função, críticas construtivas e avaliações sobre o trabalho, solicitações de assiduidade do trabalhador, dentre outras. No entanto, as cobranças devem ser feitas de forma explícita e não vexatória (Hirigoyen, 2006; Tolfo \& Oliveira, 2013).

Piñuel (2013) relaciona outras situações que não são consideradas assédio: ter um dia ruim no trabalho; ter um chefe perfeccionista; ter um conflito pontual com outra pessoa; ter muito trabalho e pouco tempo para executá-lo; estar estressado; trabalhar em um ambiente com clima conflituoso; ter uma discussão ou desacordo pontual; ser demitido no trabalho; ser punido por uma violação ou falha.

Dentro das organizações, um dos objetivos do assediador é chegar ao poder ou nele manter-se, ou esconder sua própria incompetência não importando quais estratégias utilizará nem quem prejudicará (Hirigoyen, 2008). Segunda a autora, o assédio é fruto de elementos que podem ser identificados e encontrados dentro das organizações, como: a) abuso de poder: o indivíduo se prevalece de sua posição hierárquica e persegue seu alvo. Tal ocorrência pode ter um efeito cascata, da mais alta chefia ao menor chefe na escala; b) manipulação perversa: o indivíduo busca se engrandecer, e sente necessidade de rebaixar os demais.

As causas da ocorrência do assédio moral podem ser diversas, desde questões pessoais como inveja e desgosto de outrem, até situações promovidas por uma cultura que favorece e/ou 
beneficia o agressor em decorrência ao alcance de determinada meta/objetivo (Nunes, 2011; Nunes \& Tolfo, 2012). Ou seja, é uma situação difícil de ser identificada, pois em determinados momentos a estratégia utilizada pelo agressor é sutil e atinge a vítima aos poucos sem deixar ela reagir a tempo, de modo a parecer que os atos negativos são brincadeiras corriqueiras (Hirigoyen 2008; 2006; Einarsen, Hoel, Zapf \& Cooper, 2003; 2011). Assim, o conhecimento prévio do conceito e suas características são essenciais para o início da prevenção e conhecimento desse fenômeno tão antigo quanto o próprio trabalho.

\section{Método}

A pesquisa desenvolvida neste artigo foi classificada como descritiva, com uma abordagem qualitativa. Buscou-se descrever a definição de assédio moral no trabalho em um termo/palavra tendo como público-alvo trabalhadores das mais diversas áreas de atuação. Para tanto, a pesquisa compreendeu três outras pesquisas distintas desenvolvidas nos anos de 2008, 2010, 2014 e 2015, as quais tinham como mesma pergunta aos participantes "Defina assédio moral em um termo/palavra". O lócus, ano, público-alvo e quantidade de participantes desta pesquisa pode ser identificado no Quadro 2 a seguir.

Quadro 2 - Origem dos dados da pesquisa.

\begin{tabular}{|c|l|lc|}
\hline ANO & \multicolumn{1}{|c|}{ LOCAL DE PESQUISA } & \multicolumn{1}{c|}{ PÚBLICO-ALVO } & QNT \\
\hline 2008 & $\begin{array}{l}\text { Seis cursos de especialização da Fundação de Estudos } \\
\text { e Pesquisas Socioeconômicos (Fepese/UFSC) }\end{array}$ & $\begin{array}{l}\text { Alunos (profissionais } \\
\text { diversas áreas) }\end{array}$ & 124 \\
\hline 2010 & Universidade Federal de Santa Catarina & $\begin{array}{l}\text { Servidores (docentes e técnicos- } \\
\text { administrativos) }\end{array}$ & 234 \\
\hline $\begin{array}{c}2014- \\
2015\end{array}$ & Universidade Federal de Santa Catarina & $\begin{array}{l}\text { Servidores (docentes e técnicos- } \\
\text { administrativos) }\end{array}$ & 183 \\
\hline
\end{tabular}

Fonte: Elaborado pelos autores (2015).

Portanto, a coleta de dados ocorreu em três momentos distintos. Em 2008 houve a aplicação de questionário presencial com seis turmas de cursos de especialização, logo, entrouse em contato com os coordenadores e professores dos cursos para agendar a sua aplicação. Em 2010 e 2014-2015 o questionário foi aplicado online, sendo divulgado prioritariamente por $e$ mail aos servidores da UFSC. Ao total, a pesquisa compreendeu 541 respondentes das mais diversas áreas e setores de atuação, principalmente do ambiente universitário.

Em relação à análise de dados, as informações obtidas foram tratadas por software estatístico e agrupadas em duas categorias: consequência/efeito (a definição do assédio moral como consequência ou efeito que a violência pode proporcionar à vítima); prática hostil 
(definição de assédio moral como algo relacionado/perpetrado pela organização e consequentemente seus indivíduos).

\section{Interpretação e Análise dos Dados}

Antes de iniciar a análise e apresentação dos dados, é importante apresentar uma breve caracterização do público-alvo da pesquisa. Conforme já mencionado, este artigo é fruto de três pesquisas que ocorreram em três momentos distintos: 2008, 2010, e 2014-2015. Ressalta-se que nos anos de 2010 e 2014-2015 as pesquisas tiveram como foco o meio universitário federal; logo, há maior incidência de trabalhadores do setor público.

Quadro 3 -Dados representativos dos pesquisados.

\begin{tabular}{|l|c|c|}
\hline GÊNERO & FREQ. & \% \\
\hline Feminino & 306 & 56,6 \\
\hline Masculino & 234 & 43,3 \\
\hline Outros & 1 & 0,2 \\
\hline TOTAL & $\mathbf{5 4 1}$ & $\mathbf{1 0 0 , 0}$ \\
\hline SETOR DE ATUAÇÃ O & 445 & 82,3 \\
\hline Público & 86 & 15,9 \\
\hline Privado & 4 & 0,7 \\
\hline Terceiro Setor & 6 & 1,1 \\
\hline Não mencionado & $\mathbf{5 4 1}$ & $\mathbf{1 0 0 , 0}$ \\
\hline TOTAL & & \\
\hline IDADE MÉDIA & & \\
\hline \multicolumn{2}{|c}{ 40 anos } \\
\hline
\end{tabular}

Fonte: dados primários (2015)

O questionamento central realizado nas três pesquisas foi sobre o que o participante compreende por assédio moral, tendo de responder em uma palavra ou termo. Entender como o indivíduo identifica a temática é importante, uma vez que nos últimos anos o tema tem sido constantemente divulgado nas mídias e está presente nas pesquisas acadêmicas e no ambiente de trabalho, o que pode levar à sua banalização e interpretação errônea (Nunes, 2016).

A partir das respostas e relatos apresentados pelos participantes, estes foram agrupados em: a) consequência/efeito: a definição do assédio moral como consequência do que a violência pode proporcionar à vítima; b) prática hostil: definição de assédio moral relacionado à ação e/ou comportamento hostil perpetrado pelo agressor/organização. Portanto, a análise acontecerá por estas duas variáveis - consequência/efeito e prática hostil.

De modo geral, constatou-se que 3\% dos participantes compreendem o assédio moral por meio da consequência ou efeito que ele pode proporcionar, e a grande maioria, 97\% 
visualizam a violência pelas estratégias hostis. Em ambas categorias serão apresentados os termos mais incidentes, e em cada uma delas será feita uma correlação diferente, na primeira com a questão de gênero, e a segunda pelo setor da organização. Entende-se assim que essas correlações podem mostrar algumas diferenças significativas.

Tabela 1 - Compreensão ao assédio moral em 1 termo: consequência/efeito.

\begin{tabular}{|l|c|c|}
\hline CONSEQUÊNCIA/EFEITO & FREQ. & \% \\
\hline Vergonha & 4 & 25,0 \\
\hline Medo & 3 & 18,8 \\
\hline Raiva & 2 & 12,5 \\
\hline Angústia & 1 & 6,3 \\
\hline Baixa autoestima & 1 & 6,3 \\
\hline Culpa & 1 & 6,3 \\
\hline Dignidade & 1 & 6,3 \\
\hline Ódio & 1 & 6,3 \\
\hline Sofrimento & 1 & 6,3 \\
\hline Tristeza & 1 & 6,3 \\
\hline TOTAL & $\mathbf{1 6}$ & $\mathbf{1 0 0 , 0}$ \\
\hline
\end{tabular}

Fonte: dados primários (2015)

As respostas compreendem os efeitos/consequências do assédio moral levantadas pelos participantes. Os itens com maior frequência foram vergonha, medo e raiva. Segundo Soboll (2008), o sentimento de vergonha vem acompanhado por sentimentos de inferioridade e de exposição. Para a autora, a vergonha evidencia a vulnerabilidade de estar no olhar do outro para ser julgado, e se tal julgamento for negativo, a vergonha vem acompanhada de culpa, medo, sofrimento e afeta diretamente sua identidade.

Em relação ao sentimento de culpa, atribui-se à vítima que ela é a própria culpada pela ocorrência de assédio moral. Ou seja, a culpa pela ocorrência da violência não é do agressor, e sim do alvo. Segundo Freitas et al. (2008) em algumas práticas relacionadas com a eliminação de determinadas pessoas nas organizações existe uma tendência a responsabilizar o indivíduo assediado pelo surgimento de tais situações. Com o tempo o indivíduo passa a ter uma avaliação negativa de si, e questiona-se onde pode ter errado e/ou o que ter feito para merecer tais situações (Garcia \& Tolfo, 2011). Ou seja, inverte-se totalmente a responsabilidade das ações hostis perpetradas.

Ao relacionar a categoria por gênero, identificamos maior incidência do sexo masculino na definição de assédio moral em um termo como uma consequência/efeito, conforme pode ser identificado na Tabela 2. 
Tabela 2 - Compreensão ao assédio moral em um termo: consequência/efeito por gênero.

\begin{tabular}{|c|c|c|c|}
\hline $\begin{array}{c}\text { CONSEQUÊNCIA/EFEITOS / } \\
\text { GÊNERO }\end{array}$ & FEM. & MASC. & TOTAL \\
\hline Vergonha & 1 & 3 & 4 \\
\hline Medo & 2 & 1 & 3 \\
\hline Raiva & 0 & 2 & 2 \\
\hline Angústia & 0 & 1 & 1 \\
\hline Baixa autoestima & 1 & 0 & 1 \\
\hline Culpa & 0 & 1 & 1 \\
\hline Dignidade & 0 & 1 & 1 \\
\hline Ódio & 0 & 1 & 1 \\
\hline Sofrimento & 0 & 1 & 1 \\
\hline Tristeza & 1 & 0 & 1 \\
\hline TOTAL & 5 & 11 & 16 \\
\hline
\end{tabular}

Fonte: dados primários (2015)

Em especial, os homens, apresentaram maior incidência no item Vergonha (3). Tanto a vergonha quanto o medo e raiva são consequências que frequentemente aparecem nas pesquisas de assédio moral. Em especial sobre a vergonha, ao remetermos a questão por gênero, no caso do sexo masculino, a vergonha é ainda maior, pois, há a questão do machismo (Hirigoyen, 2006).

Devido à "cultura machista", os homens, de modo geral, não conseguem expor que sofreram ou sofrem situações de assédio moral. Os homens sofrem muito porque sua socialização não está pensada em viver uma situação como esta (Quiñones, Cantera \& Moré, 2013). As mulheres, por medo de perder o trabalho e não poder ajudar no sustento de casa ou para manter seus filhos sendo mulher solteira, acabam por aguentar mais as violências que os homens (Quiñones et al., 2013). Por essa cultura machista já arraigada na sociedade desde os primórdios da civilização, o homem expressa mais raiva que as mulheres, e elas, por sua vez, tendem a aguentar/segurar mais.

Apesar de a maioria das pesquisas apontarem que as mulheres são, estatisticamente falando, as maiores vítimas do assédio moral, também são elas as que mais procuram ajuda médica ou psicológica e, não raro, no seu próprio grupo de trabalho, verbalizando suas queixas, pedindo ajuda. Em relação ao homem, sob alguns aspectos, essa situação é mais delicada, pois fere sua identidade masculina. Em um tipo de agressão que, como já vimos, é paulatina e quase invisível, não raro quando a vítima se apercebe da situação o fenômeno destrutivo já se estabeleceu, o que a leva a um processo depressivo em que não encontra mais forças e em relação a que nem mesmo possui ânimo para reagir. Essa atitude de aparente passividade, ou melhor, de ausência de ação, dentro de nossa cultura machista e preconceituosa é vista mais como um atributo feminino do que masculino, o que piora o quadro depressivo da vítima, pois rebaixa ainda mais sua autoestima, ferindo sua identidade masculina. Assim, no caso masculino, tornar pública a sua humilhação associa-se a admitir sua impotência diante dos fatos, o que se lhe configura como o "fundo do poço", o auge de sua forçada degradação (Heloani, 2005, p. 105). 
Por sua vez, a visualização do assédio pela prática hostil - que compreende as situações hostis perpetradas pelos indivíduos/organização, apresentam maior frequência nas respostas $(97 \%)$. Os itens com frequência inferior a 5 (menores que 1,0\%) foram alocados no item Outros.

Tabela 3 - Compreensão ao assédio moral em 1 termo: prática hostil,

\begin{tabular}{|l|c|c|}
\hline \multicolumn{1}{|c|}{ PRÁTICA HOSTIL } & FREQ. & $\%$ \\
\hline Humilhação & 71 & 13,5 \\
\hline Desrespeito & 67 & 12,8 \\
\hline Abuso & 55 & 10,5 \\
\hline Constrangimento & 45 & 8,6 \\
\hline Coação & 18 & 3,4 \\
\hline Violência & 18 & 3,4 \\
\hline Perseguição & 17 & 3,2 \\
\hline Pressão & 17 & 3,2 \\
\hline Intimidação & 15 & 2,9 \\
\hline Agressão & 9 & 1,7 \\
\hline Ameaça & 8 & 1,5 \\
\hline Crime & 7 & 1,3 \\
\hline Abuso de poder & 6 & 1,1 \\
\hline Covardia & 6 & 1,1 \\
\hline Desconforto & 6 & 1,1 \\
\hline Ofensa & 6 & 1,1 \\
\hline Poder & 6 & 1,1 \\
\hline Autoritarismo & 5 & 1,0 \\
\hline Coerção & 5 & 1,0 \\
\hline Opressão & 5 & 1,0 \\
\hline Outros & 133 & 25,3 \\
\hline TOTAL & $\mathbf{5 2 5}$ & $\mathbf{1 0 0 , 0}$ \\
\hline
\end{tabular}

Fonte: dados primários (2015)

A palavra com maior frequência foi humilhação com 13,5\% das respostas, seguida por desrespeito com $12,8 \%$, abuso com 10,5\% e constrangimento com 8,6\%. A humilhação consiste em uma consequência específica do assédio moral, segundo Hirigoyen (2006, p. 172), “o que há em comum nos quadros de assédio em relação às outras formas de sofrimento no trabalho é a predominância da vergonha e da humilhação”. Barreto (2006, p. 168) corrobora ao expor que "a humilhação rompe temporalidades, reforça o sentimento de inutilidade, comprometendo a identidade e a dignidade". O desrespeito e abuso estão relacionados aos atos e comportamentos em si, este último, encontra-se em consonância com a própria definição de assédio moral apresentada por Hirigoyen (2008, p. 65) "Assédio moral é toda e qualquer conduta abusiva [...]". No item Outros, encontram-se palavras como: imoral, invasão, prepotência, dominação, repressão, amoral, desprezo, discriminação, imposição, inaceitável, maldade, perturbação, terrorismo, tortura, e demais. 
Quando relacionamos essa categoria com os setores de trabalho dos participantes, conforme Tabela 4, identificamos que tanto no setor privado quanto no público as palavras com maior frequência se repetem: humilhação, desrespeito, abuso, constrangimento.

Tabela 4 - Compreensão ao assédio moral em 1 termo: prática hostil por setor.

\begin{tabular}{|l|c|c|c|c|c|}
\hline \multicolumn{1}{|c|}{ PRÁTICA } & Não mencionado & $\mathbf{3}^{\text {' }}$ Setor & Privado & Público & TOTAL \\
\hline Humilhação & 0 & 0 & 10 & 61 & $\mathbf{7 1}$ \\
\hline Desrespeito & 2 & 1 & 19 & 45 & $\mathbf{6 7}$ \\
\hline Abuso & 1 & 0 & 18 & 36 & $\mathbf{5 5}$ \\
\hline Constrangimento & 0 & 0 & 8 & 37 & $\mathbf{4 5}$ \\
\hline Coação & 0 & 0 & 1 & 17 & $\mathbf{1 8}$ \\
\hline Violência & 0 & 0 & 0 & 18 & $\mathbf{1 8}$ \\
\hline Perseguição & 0 & 0 & 0 & 17 & $\mathbf{1 7}$ \\
\hline Pressão & 0 & 1 & 1 & 15 & $\mathbf{1 7}$ \\
\hline Intimidação & 0 & 0 & 0 & 15 & $\mathbf{1 5}$ \\
\hline Agressão & 0 & 0 & 1 & 8 & $\mathbf{9}$ \\
\hline Ameaça & 0 & 0 & 0 & 8 & $\mathbf{8}$ \\
\hline Crime & 0 & 0 & 1 & 6 & $\mathbf{7}$ \\
\hline Abuso de poder & 0 & 0 & 0 & 6 & $\mathbf{6}$ \\
\hline Covardia & 0 & 0 & 1 & 5 & $\mathbf{6}$ \\
\hline Desconforto & 0 & 0 & 1 & 5 & $\mathbf{6}$ \\
\hline Ofensa & 0 & 1 & 3 & 2 & $\mathbf{6}$ \\
\hline Poder & 1 & 0 & 0 & 5 & $\mathbf{6}$ \\
\hline Autoritarismo & 0 & 0 & 1 & 4 & $\mathbf{5}$ \\
\hline Coerção & 0 & 0 & 0 & 5 & $\mathbf{5}$ \\
\hline Opressão & 0 & 0 & 0 & 5 & $\mathbf{5}$ \\
\hline Outros & 2 & 1 & 20 & 110 & $\mathbf{1 3 3}$ \\
\hline TOTAL & $\mathbf{6}$ & $\mathbf{4}$ & $\mathbf{8 5}$ & $\mathbf{4 3 0}$ & $\mathbf{5 2 5}$ \\
\hline
\end{tabular}

A humilhação consiste em uma consequência específica do assédio moral, segundo Hirigoyen (2006, p. 172), “[...] o que há em comum nos quadros de assédio em relação às outras formas de sofrimento no trabalho é a predominância da vergonha e da humilhação". Barreto (2006, p. 168) corrobora ao expor que "a humilhação rompe temporalidades, reforça o sentimento de inutilidade, comprometendo a identidade e a dignidade". O desrespeito e abuso estão relacionados aos atos e comportamentos em si; este último, encontra-se em consonância com a própria definição de assédio moral apresentada por Hirigoyen (2008, p. 65) "assédio moral é toda e qualquer conduta abusiva $[\ldots]$ ".

Ressalta-se que as formas de assédio moral são diferentes de um setor privado para o público. No setor privado é mais evidente, dura menos e termina em geral com a saída da vítima (Hirigoyen, 2006). Nas empresas de pequeno e médio porte, é que se localizam os casos de assédio moral deliberado e consciente, com o objetivo de fazer o funcionário pedir demissão. Segundo a autora, o assédio moral mais ostensivo, beirando algumas vezes o sadismo, é visto 
em pequenas empresas, onde não há nenhuma instância coletiva para intervir nessas situações. Já no setor público o assédio pode durar anos, pois a rigor, as pessoas são protegidas e não podem ser demitidas, pois têm estabilidade profissional, a não ser devido a uma falta muito grave. Nas empresas públicas, os casos de assédio moral são mais visíveis e também divulgados pela mídia (Hirigoyen, 2006).

Na pesquisa o item "Abuso de Poder" teve apenas incidência (6) no Setor Público, no entanto segundo Hirigoyen (2006) e Einarsen et al. $(2003 ; 2005 ; 2011)$ o abuso de poder é algo frequente tanto em empresas privadas quanto em públicas. "Como o setor público está voltado para o bem público, dentro de um esquema social, os abusos que lá ocorrem parecem chamar mais a atenção. Nota-se geralmente que o assédio moral não está relacionado à produtividade, mas às disputas de poder" (Hirigoyen, 2006, p. 125).

Independente do setor, do gênero, e se o participante compreende o assédio moral como uma consequência/efeito ou prática hostil, o fato é que a violência precisa ser coibida e combatida principalmente pelos gestores organizacionais, que se omitem ou incentivam sua prática devido ao alcance dos objetivos fins da organização e pela busca de metas (Nunes \& Tolfo, 2015).

\section{Considerações Finais}

O assédio moral no trabalho atualmente é um tema muito discutido no ambiente acadêmico, profissional, jurídico e nas mídias. A incompreensão dessa problemática pode levar a banalizar e interpretar de maneira incorreta o significado e alcance do problema.

Nesta pesquisa buscou-se descrever a definição de assédio moral no trabalho em um termo a partir do relato dos participantes em momentos distintos, 2008, 2010, 2014-2015. A maioria das palavras tem conotação com o tema, seja termos utilizados nas definições e conceitos dos autores ou como também uma consequência da própria violência. Logo, compreendemos que seria necessário classificar os termos entre consequências/efeitos ou prática hostil.

Nos categoria consequências/efeitos, os participantes compreendem o assédio moral como: vergonha, medo, raiva, angústia, baixa autoestima, culpa, perda de dignidade, ódio, sofrimento, tristeza. Ou seja, veem a violência como uma de suas consequências. Na categoria prática hostil, os pesquisados entendem o assédio moral como algo relacionado à organização (e seus indivíduos) proporcionam: humilhação, desrespeito, abuso, constrangimento. Ao 
realizarmos o cruzamento de dados entre o entendimento de assédio com o setor organizacional a fim de descobrir qual termo é mais utilizado em um ou em outro, verificamos que eles seguem um padrão (tendo como base o setor público e privado que tiveram maior frequência de respostas).

Não obstante ao entendimento dos pesquisados sobre o tema, muitos comentaram sobre o conhecimento da ocorrência de casos de assédio moral, seja pela vivência de situações hostis ou também pela observação de situações que ocorrem em seu ambiente de trabalho com colegas. Este trabalho se finaliza apresentando que existe muita similaridade da frequência dos termos apresentados pelos pesquisados desde 2008 até 2015. Ou seja, apesar de que em 2008 o assédio moral não era um tema muito divulgado e pesquisado, a população pesquisada compreendeu o assédio moral da mesma forma que os pesquisados de 2010, 2014 e 2015.

\section{Agradecimentos}

Agradecimentos especiais à Coordenação de Aperfeiçoamento de Pessoal de Nível Superior (Capes) pelo apoio e financiamento destinado ao projeto ao qual este trabalho científico se originou. Bolsista da Capes - Processo BEX 9426/14-0.

\section{Referências}

Barreto, M. M. S. (2006). Violência, saúde e trabalho: uma jornada de humilhações. São Paulo: Educ.

Beswick, J.; Gore, J.; \& Palferman, D. (2006). Bullying at work: A review of the literature. Health and Safety Laboratory.

Einarsen, S.; Hoel, H.; Zapf, D.; \& Cooper, C. L. (2003). The concept of bullying at work: the european tradition. In: Einarsen, S., Hoel, H, Zapf, D. \& Cooper, C. L. (Orgs.). Bullying and emotional abuse in the workplace: International perspectives in research and practice (pp. 330). London: Taylor \& Francis.

(2005). Workplace Bullying: individual pathology or organizational culture? In: Bowie, V.;

Fischer, B. S.; \& Cooper, C. L. (Orgs.). Workplace violence: issues, trends, strategies (pp. 229247). Devon: Willian Publishing. 
(2011). The concept of bullying and harassment at work: the european tradition. In: Einarsen, S., Hoel, H, Zapf, D. \& Cooper, C. L (Orgs.). Bullying and harassment in the workplace: Developments in theory, research, and practice (pp. 3-39). London: Taylor \& Francis.

Freitas, M. E.; Heloani, J. R.; \& Barreto, M. M. S. (2008). Assédio moral no trabalho. Cengage Learning, São Paulo.

Garcia, I. S. \& Tolfo, S. R. (2011). Assédio moral no trabalho: culpa e vergonha pela humilhação social. Curitiba: Juruá.

Heloani, R. (2005). Assédio moral: a dignidade violada. Aletheia, Canoas. 22(1), 101-108.

Hirigoyen, M.-F. (2006). Mal-estar no trabalho: redefinindo o assédio moral (3a ed.). Rio de Janeiro: Bertrand Brasil.

. (2008). Assédio moral: a violência perversa no cotidiano (10a ed.). Rio de Janeiro: Bertrand Brasil.

Leymann, H. (1990). Mobbing and psychological terror at workplaces. Violence and Victims, 5(2), 119-126.

. (1996). The content and development of mobbing at work. European Journal of Work and Organizational Psychology, 5(2), 165-184.

Nunes, T. S. (2011). Assédio moral no trabalho: o contexto dos servidores da Universidade Federal de Santa Catarina. Florianópolis. (Dissertação de mestrado). Programa de Pós-graduação em Administração, Universidade Federal de Santa Catarina, Florianópolis, Santa Catarina, Brasil. . (2016). A influência da cultura organizacional na ocorrência do assédio moral no trabalho na Universidade Federal de Santa Catarina. (Tese de doutorado). Programa de Pós-graduação em Administração, Universidade Federal de Santa Catarina, Florianópolis, Santa Catarina, Brasil. 
Nunes, T. S. \& Tolfo, S. R. (2012) Assédio moral no trabalho: consequências identificadas por servidores docentes e técnico-administrativos em uma universidade federal brasileira. Revista Gestão Universitária na América Latina - GUAL, Florianópolis, 5(3), 264-286.

Nunes, T. S. \& Tolfo, S. R. (2013a). A dinâmica e os fatores organizacionais propiciadores à ocorrência do assédio moral no trabalho. Revista de Gestão e Secretariado - GeSec, São Paulo, $4(2), 90-113$.

. (2013b). Acoso moral en el trabajo: políticas y prácticas de prevención y combate en una institución de enseñanza superior brasileña. In: Martin, F. P. S. (coord.). Desvelar al mobbing: asegurar la dignidad en las organizaciones I (pp. 53-70). México: Ediciones y Gráficos Eón. . (2015). O assédio moral no contexto universitário: uma discussão necessária. Revista de Ciências da Administração, Florianópolis, 17(41), 21-36.

Piñuel, I. (2013). Por si acaso te acosan ...: 100 cosas que necesitas saber para salir del acoso psicológico en el trabajo. Buenos Aires: Códice.

Quiñones, P., Cantera, L. M. \& Moré, C. L. O. O. (2013). La violencia relacional en contextos laborales que trabajan contra la violencia. In: Cantera, L. M., Pallarès, S. \& Selva, C. Del malestar al bienestar laboral (pp. 135-155). Barcelona: Amentia.

Sina, A. (2007). A outra face do poder. São Paulo: Saraiva.

Soboll, L. A. P. (2008). Assédio moral/organizacional: uma análise da organização do trabalho. São Paulo: Casa do Psicólogo.

Tolfo, S. R., \& Oliveira, R. T. (2013). Assédio moral no trabalho: uma violência a ser enfrentada. Florianópolis, UFSC. 